\title{
CARNE SUÍNA E SUAS POSSÍVEIS DOENÇAS ENZOÓTICAS
}

\author{
SWINE AND YOUR POSSIBLE ENZOTIC DISEASES
}

\author{
Ana Beatriz do Carmo - beacarmo17@gmail.com \\ Daniela Rodolpho - danirodolpho@yahoo.com.br \\ Faculdade de Tecnologia de Taquaritinga (FATEC) -SP -Brasil \\ DOI: 10.31510/infa.v16i2.659
}

\begin{abstract}
RESUMO
O Brasil se destaca por ser o quarto maior produtor e exportador de carne suína, um grande expoente na produção e na exportação de suínos e derivados. O manejo da produção é também parte essencial para garantir a qualidade da carne e compreende a incorporação de metodologias, processos, produtos e tecnologias ao processo produtivo. Porém, vem causando vários mitos, devido a caso de doenças enzoóticas presentes na carne, alguns aspectos relacionados à infraestrutura laboratorial, às medidas de biossegurança e aos cuidados necessários para impedir que determinadas doenças, ainda exóticas, infectem o rebanho brasileiro. $\mathrm{O}$ estudo teve como objetivo avaliar a espécie e o bem-estar do suíno, tendo uma ampla base do teor de doenças micro-organismos presente na carne e analisar a qualidade e os benefícios que a carne pode trazer aos consumidores, como também, a abordagem de possíveis preocupações existentes em suínos contaminados por doenças enzoóticas que causam prejuízos para a produção da carne suína no Brasil, podendo alterar a demanda de consumidores e até mesmo na produtividade e nas exportações. Despertou interesse em se aprofundar no assunto, para obter mais informações sobre a carne que consumimos no nosso dia a dia.
\end{abstract}

Palavras-chave: Infraestrutura. Biossegurança. Patógenos.

\begin{abstract}
Brazil stands out for being the fourth largest producer and exporter of pork, a major exponent in the production and exportation of pork and meat products. Production management is also an essential part of ensuring meat quality and includes the incorporation of methodologies, processes, products and technologies into the production process. However, it has caused several myths, due to the case of enzootic diseases present in the meat, some aspects related to laboratory infrastructure, biosecurity measures and the necessary precautions to prevent certain diseases, still exotic, from infecting the Brazilian herd. The aim of the study was to evaluate the species and welfare of the pig, having a broad base of the microorganism disease content present in the meat and to analyze the quality and benefits that the meat can bring to the consumers, as well as the approach of possible concerns in pigs contaminated by enzootic diseases that cause damage to pork production in Brazil, which may alter consumer demand and even productivity and exports. He was interested in going deeper into the subject, for more information about the meat we eat in our daily lives.
\end{abstract}


Keywords: Infrastructure. Biosecurity. Pathogens.

\section{INTRODUÇÃO}

Dentre as proteínas consumidas mundialmente, a carne suína é a mais demandada, seguida pela carne de aves e, em terceiro lugar, pela carne bovina. Considerando-se o potencial do Brasil para a produção de suínos, pode-se inferir que o consumo interno é muito baixo quando comparado ao consumo de outros países (ABIPECS, 2013).

Segundo Bridi, Rubensam e Lobato (2000), definir a qualidade da carne suína representa algo bastante amplo e complexo. Existe um grande número de fatores intrínsecos (relacionados ao animal) e extrínsecos que participam de todas as fases da cadeia (da concepção até o preparo final do produto para consumo), e que se interagem e influenciam as diferentes características relacionadas com a qualidade da carne.

Diante desse tema, foi pesquisado que a carne suína, em alguns animais, que não foram cuidados corretamente, contém a presença de micro-organismos na carne suína e o resultado da contaminação dos animais vivos, dos equipamentos, dos manipuladores e do ambiente de processamento demostra a importância em se manejar os riscos associados à segurança da carne, desenvolvendo estratégias de controle dos patógenos em todas as etapas do processamento e também uma doença enzoóticas, também denominadas de doenças de rebanho ou doenças endêmicas (FABLET, 2009).

Essas doenças endêmicas ocorrem em grande parte das granjas tecnificadas de produção de suínos, onde há ampla microbiota de patógenos importantes, que se mantêm em equilíbrio dentro dos rebanhos e são controlados pelas defesas imunes dos animais, pelos cuidados adequados com os fatores predisponentes e pelo uso de medicamentos.

Cabe destacar que também há patógenos nos suínos que não provocam doença clínica, mas que são importantes na segurança dos alimentos, como, por exemplo, algumas sorovares de Salmonella (BEARSON et al., 2013).

Entre tanto, aprofundando mais no tema abordado há patógenos importantes, que se mantêm em equilíbrio dentro dos rebanhos e são controlados pelas defesas imunes dos animais, pelos cuidados adequados com os fatores predisponentes e pelo uso de medicamentos. A estratégia mais comum é permitir as infecções enzoóticas, mas impedir a multiplicação significativa dos agentes, para que a infecção não atinja o estágio de doença (FABLET, 2006). 


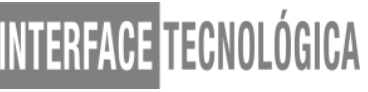

Há também uma maior exigência dos consumidores quanto ao bem-estar animal e à segurança dos alimentos. Isso reforça a importância da adoção de instalações e medidas de manejo adequadas para prevenir doenças e sua disseminação.

O presente estudo tem como objetivo avaliar a espécie e o bem-estar do suíno, tendo uma ampla base do teor de doenças micro-organismos presente na carne e analisar a qualidade e os benefícios que a carne pode trazer aos consumidores, como também, a abordagem de possíveis doenças enzoóticas que causam prejuízos para a produção da carne suína no Brasil, podendo alterar a demanda de consumidores e até mesmo na produtividade e nas exportações.

\section{FUNDAMENTAÇÃO TEÓRICA}

\subsection{Qualidade da carne suína}

Definir a qualidade da carne suína representa algo bastante amplo e complexo. Existe um grande número de fatores intrínsecos (relacionados ao animal) e extrínsecos que participam de todas as fases da cadeia (da concepção até o preparo final do produto para consumo), e que se interagem e influenciam as diferentes características relacionadas com a qualidade da carne (BRIDI et al., 2003).

A atribuição da qualidade à carne também varia entre os diferentes mercados, é percebida de forma distinta para cada segmento da cadeia (produtor, indústria e consumidor), sendo igualmente diferente dependendo do nível de formação e informação do consumidor (BRIDI et al., 2003).

A importância de conhecer a composição nutricional da carne está ligada ao efeito dos nutrientes, principalmente dos lipídios, sobre a saúde humana. Sabendo que o consumo exagerado de lipídios pode aumentar as chances de doença cardiovascular que é uma das principais causas de morte no Brasil e em muitos países.

No Quadro 1 há uma comparação entre carne suína e a carne de outros animais.

Os consumidores têm se preocupado mais com o conteúdo nutricional das carnes, mas é importante diferenciar com as demais espécies, a composição nutricional destas. Em alguns casos, um manejo de baixa qualidade, não dando os cuidados necessários para o animal, não aplicando vacinas pode acarretar vários problemas futuramente. 


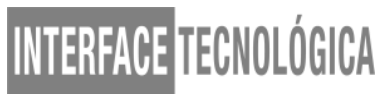

QUADRO 1 - Registro de lipídio presente na carne suína.

\begin{tabular}{|c|c|c|}
\hline Carne & Colesterol (mg/100g) ${ }^{1}$ & Lipídios totais $(\mathrm{g} / 100 \mathrm{~g})^{2}$ \\
\hline \multicolumn{3}{|l|}{ Bovina } \\
\hline Contrafilé & 51,0 & 2,4 \\
\hline Coxão mole & 56,0 & 1,7 \\
\hline Coxão duro & 50,0 & 1,9 \\
\hline \multicolumn{3}{|l|}{ Suína } \\
\hline Lombo & 49,0 & 3,0 \\
\hline Pernil & 50,0 & 5,0 \\
\hline Toucinho & 54,0 & 83,0 \\
\hline \multicolumn{3}{|l|}{ Frango } \\
\hline Carne branca & 58,0 & 2,7 \\
\hline Carne escura & 80,0 & 7,0 \\
\hline Pele & 104,0 & 56,0 \\
\hline
\end{tabular}

Fonte: BRAGAGNOLO (2001).

\subsection{Benefícios da carne suína}

Pesquisas mostram a importância do consumo da carne suína para o tratamento de doenças, como hipertensão arterial e anemia. Uma das virtudes da carne suína é o seu alto teor de potássio, pois ele ajuda a regular os níveis de sódio no corpo, exigindo menos sal para consumo (GEESDORF, 2010). A carne suína é pobre em sódio e rica em potássio. A grande maioria dos estudos mostra que a ingestão de uma grande quantidade de sal aumenta a pressão arterial e, para o controle da pressão arterial, uma das recomendações é que a relação potássio-sódio seja pequena. A carne suína possui a razão potássio-sódio em torno de 7 , ou seja, é altamente favorável ao controle da pressão arterial (BRAGAGNOLO, 2013).

A carne suína é também recomendada para crianças em fase de crescimento, pois ela apresenta proteínas de alto valor biológico, ácidos graxos monoinsaturados, vitaminas do complexo B, ferro e selênio. Dessa forma, a carne suína deve ser mais uma opção nutricionalmente adequada ao cardápio escolar, pois seus nutrientes são indispensáveis para o crescimento progressivo de crianças nessa idade escolar (GEESDORF, 2010). 


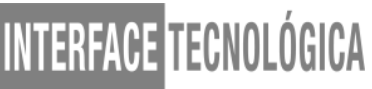

\subsection{Preocupações da carne suína}

E para relatar as preocupações que envolve a carne suína, há doenças que diante de pesquisas, há possibilidades de fazer mal ao ser consumida. Mudanças no perfil epidemiológico das doenças dos suínos podem ser observadas na atualidade. As doenças com maior impacto na produção eram as bacterianas, que, por sua vez, resolviam-se com tratamentos antimicrobianos.

Contudo, recentemente, as principais doenças de suínos relatadas são multifatoriais e virais, geralmente imunossupressoras, e causam elevada morbidade, mortalidade variável e, principalmente, redução no desempenho com aumento no custo de produção (BRUM et al., 2013). Essas doenças, somam-se agentes oportunistas, causadores de complexos de doenças dos sistemas respiratório, digestório e urinário (BRUM et al., 2013).

Além disso, também há maior exigência dos consumidores quanto ao bem-estar animal e à segurança dos alimentos. Isso reforça a importância da adoção de instalações e medidas de manejo adequadas para prevenir doenças e sua disseminação.

\subsection{Doenças}

O Brasil obteve, recentemente, reconhecimento internacional de zona livre de peste suína clássica (PSC). Esse reconhecimento englobou grande parte do território nacional e implica no atendimento de requisitos sanitários a serem cumpridos pelos estados. Já a peste suína africana (PSA) foi registrada no País na década de 1980, mas foi erradicada por abate sanitário, e, desde então, não houve mais relatos da doença (SANTOS, 2017).

Com relação ao vírus da Síndrome Reprodutiva e Respiratória dos Suínos (PRRS), vários estudos epidemiológicos foram realizados no Brasil a partir de 1995, principalmente em plantéis de granjas que importaram suínos e das Granjas de Reprodutores Suínos Certificada (GRSC), porém, não foi possível identificar nem o vírus nem a doença clínica.

Doença, como triquinelose, é uma enfermidade causada por um parasita chamado Trichinela spiralis, que é encontrado em vários carnívoros e onívoros, dentre eles os suínos. O Homem se contamina ao ingerir carne crua ou mal passada de animais que possuam a larva deste parasita em forma de cisto nos seus músculos (DIEHL, 2011). 
A Figura 1 mostra o ciclo da doença triquinelose.

FIGURA 1 - Ciclo da doença Triquinelose.

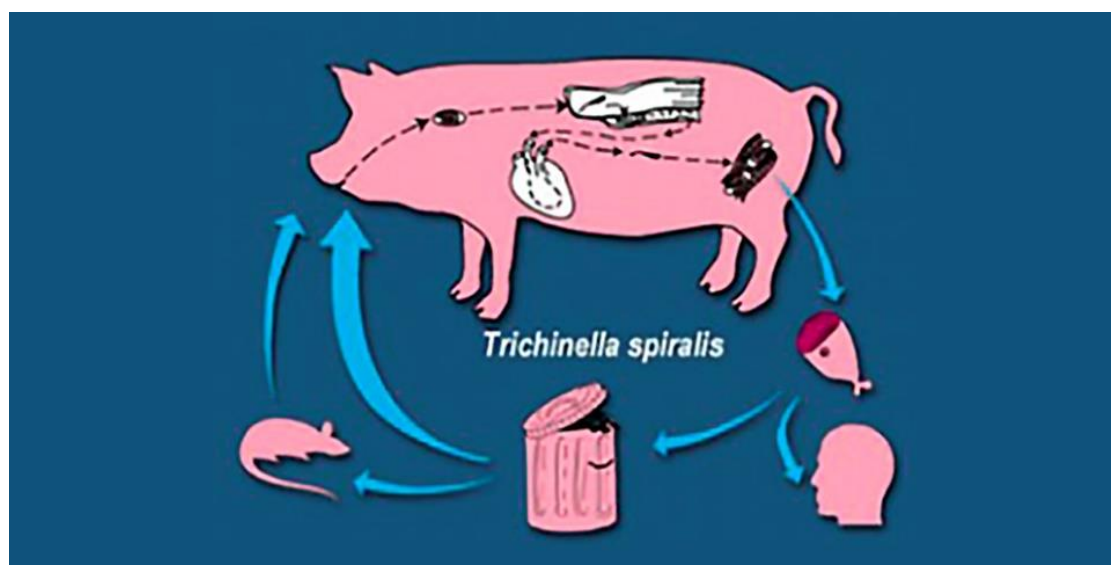

Fonte: Saúde Animal (2012)

No Brasil a incidência da triquinelose na suinocultura tecnificada é praticamente nula, pois nas análises obrigatórias realizadas pelas agroindústrias exportadoras, por exigências dos países importadores, não tem mostrado nenhum caso positivo (DIEHL, 2011).

\section{PROCEDIMENTOS METODOLÓGICOS}

A metodologia utilizada para o desenvolvimento deste artigo consistiu-se em uma revisão bibliográfica. Segundo Gil (2006) uma pesquisa bibliográfica é feita com o auxílio de material já existente, que permite ao pesquisador reconhecer o passado histórico e os aspectos atuais da área pesquisada. Com esse pensamento foram utilizados referencias já publicados e estudadas por meio de artigos científicos, livros e websites onde foram apontadas informações referentes a realidade sobre a carne suína para certificar confiabilidade e veracidade aos fatos e informações descritos.

\section{RESULTADOS E DISCUSSÃO}

O consumo de carne suína sofre grande influência positiva e negativa dos aspectos culturais da população brasileira, relacionados ao consumo, porém, está principalmente relacionada à preocupação dos consumidores com a saúde. Grande parte do território 


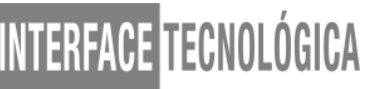

brasileiro, onde a suinocultura é tecnificada, é considerada zona livre de febre aftosa com vacinação.

De acordo com Bridi et al. (2003), a qualidade da carne suína representa algo bastante amplo e complexo. Existe um grande número de fatores relacionados ao animal e extrínsecos que participam de todas as fases da cadeia, e que se interagem e influenciam as diferentes características relacionadas com a qualidade da carne.

E segundo Diehl (2011), a incidência da triquinelose na suinocultura no Brasil é praticamente nula, pois nas análises obrigatórias realizadas pelas agroindústrias exportadoras, por exigências dos países importadores, não tem mostrado nenhum caso positivo.

Em relação entre ambas informações pode-se considerar que a sanidade do rebanho suíno nacional é apropriada e as medidas de controle utilizadas garantem elevada produtividade, mesmo assim, ainda devem ser priorizados um sistema de diagnóstico rápido e eficiente, bem como o apoio à defesa sanitária.

Para a gestão mais exemplar, é necessário evoluir na infraestrutura de diagnóstico, na vigilância epidemiológica das enfermidades, na logística de movimentação de leitões no setor produtivo e na correção de fatores de risco que favorecem a manifestação de doenças da produção dos rebanhos.

\section{CONCLUSÃO}

Diante do que foi pesquisado, a carne suína traz grandes benefícios para o consumidor humano, porém, em alguns aspectos, vem causando grandes prejuízos, tanto no manejo até no abate do animal, por exemplo, o manejo de baixa qualidade, não contribuindo na higiene e tratamentos importantes durante o nascimento ou até mesmo no desenvolvimento do suíno, com isso, podendo causar danos em fins lucrativos para o produtor, ou causando prejuízos na saúde dos consumidores.

É necessário evoluir na infraestrutura de diagnóstico, na vigilância das enfermidades, na logística de movimentação no setor produtivo, na correção de fatores de risco que favorecem a manifestação de doenças da produção e nas medidas de biosseguridade dos rebanhos. O Brasil deve estar preparado para evitar e para lidar com doenças exóticas que se tornaram endêmicas. Apesar disso, pode-se considerar que a saúde do rebanho suíno nacional 


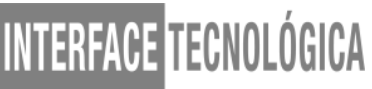

é muito boa e que as medidas de controle utilizadas garantem elevada produtividade, comprovada pelos índices produtivos semelhantes aos de países com tradição na suinocultura.

\section{REFERÊNCIAS}

ABIPECS, Associação Brasileira da Indústria Produtora e Exportadora de Carne Suína. Estatísticas. 2013. Aspectos simbólicos como determinantes dos comportamentos, Rev. Agro. Amb., v. 9, n. 4, p. 989-1005, 2016. Disponível em: <http://periodicos.unicesumar.edu.br/index.php/rama/article/viewFile/3743/2862>. Acesso em 28 Jun 2019.

BEARSON, S.M.D.; ALLEN, H.K.; BEARSON, B.L.; LOOFT, T.; BRUNELLE, B.W.; KICH, J.D.; TUGGLE, C.K.; BAYLES, D.O.; ALT, D.; LEVINE, U.Y.; STANTON, T.B. Profiling the gastrointestinal microbiota in response to Salmonella: low versus high Salmonella shedding in the porcine host. Infection, Genetics and Evolution, v.16, p.330-340, 2013.

BRAGAGNOLO, N. Carne suína faz bem ou mal? Saiba mais sobre ela, 2013. Disponível em:

<https://www.nutritime.com.br/arquivos_internos/artigos/349_-_4457-4463_-_NRE_126_nov-dez_2015.pdf>. Acesso em 26 Jun 2019.

BRAGAGNOLO, N. Aspectos comparativos entre carnes segundo a composição de ácidos graxos e teor de colesterol, 2001. Disponivel em: https://docplayer.com.br/16193913-Aspectos-comparativos-entre-carnes-segundo-acomposicao-de-acidos-graxos-e-teor-de-colesterol.html>. Acesso em 26 Jun 2019.

BRIDI A.M. et al. Efeito do genótipo halotano e de diferentes sistemas de produção na qualidade da carne suína. Revista Brasileira de Zootecnia, v.32, n.6, p.1362-1370, 2003. Disponível em: <http://www.scielo.br/pdf/rbz/v32n6/18425.pdf >. Acesso em: 08 Junho. 2019.

BRIDI, Qualidade da Carne Suína e Fatores que Influenciam, Ana Maria Bridi; Caio Abércio da Silva, 2000. Disponível em:

$<$ http://www.uel.br/grupo pesquisa/gpac/pages/arquivos/Qualidade $\% 20 \mathrm{da} \% 20 \mathrm{Carne} \% 20$ Suina $\% 20 \mathrm{e} \% 20 \mathrm{Fatores} \% 20$ que $\% 20$ Influenciam.pdf $>$. Acesso em 25 Mai 2019.

BRUM, I.R.H, et al. A infecção pelo vírus, Arq. Inst. Biol., .v.84, 2017. Disponível em: $<$ http://www.scielo.br/scielo.php?script=sci_arttext\&pid=S1808$16572017000100406 \&$ lang=pt>. Acesso em 27 Fev 2019.

CATTANI, C.S.O. et al. Métodos alternativos para contagem de micro-organismos em carcaças suínas. Ciênc. Rural, v.43, n.6, p.43-47, 2016. Disponível em: 


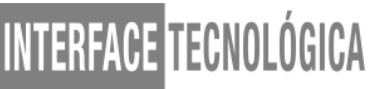

<http://www.scielo.br/scielo.php?script=sci_arttext\&pid=S0103-

$84782013000600014 \& \operatorname{lng}=\mathrm{pt} \& \operatorname{lng}=\mathrm{pt}>$. Acesso em 28 Jun 2019.

DIEHL, G.N, MITOS E VERDADES DA CARNE SUÍNA. p.04, 2011. Disponível em: $<$ https://www.agricultura.rs.gov.br/upload/arquivos/201612/02101256-inftec-13-mitos-everdades-carne-suina-n13.pdf>. Acesso em: 27 Fev 2019.

FABLET, C. An overview of the impact of the environment on enzootic respiratory diseases in pigs, 2009. p.239-260. Disponivel em:

<https://www.wageningenacademic.com/doi/abs/10.3920/978-90-8686-685-4\#page=240>. Acesso em 30 Ago 2019.

GEESDORF, C. Benefícios da carne suína na alimentação humana, Portal Dia de Campo, 2010. Disponível em:

<https://www.nutritime.com.br/arquivos_internos/artigos/349_-_4457-4463_-_NRE_12-

6_nov-dez_2015.pdf>. Acesso em 10 Ago 2019.

GIL, Antônio Carlos. Métodos e técnicas de pesquisa social. São Paulo: Editora Atlas 2006. Acesso em 05 Set 2019.

LEME, R.A, Senecavirus A: An Emerging Vesicular Infection in Brazilian Pig Herds. v 62, p. 603-611, 2015. Disponível em:

<https://onlinelibrary.wiley.com/doi/full/10.1111/tbed.12430> Acesso em: 27 Fev 2019.

MARÇAL, D.A. et al. Consumo da Carne Suína no Brasil: Aspectos Simbólicos como Determinantes dos Comportamentos. Revista em Agronegócio e Meio Ambiente, v.9, n.4, p.989-1005, 2016. Disponível em:

<http://periodicos.unicesumar.edu.br/index.php/rama/article/viewFile/3743/2862>. Acesso em 10 Ago 2019.

MIELI, M. et al. O Desenvolvimento da Suinocultura Brasileira nos Últimos 35 Anos, Cap 03, p. 85, 2003. Disponível em:

$<$ https://www.embrapa.br/documents/1355242/0/Su\%C3\%ADnos+-

+cap\%C3\%ADtulo+3.pdf>. Acesso em 26 Jun 2019.

MARCHI, A. O Consumo de Carne Suína no Brasil, Embrapa, p.29. Disponível em:

$<$ http://www.cnpsa.embrapa.br/sgc/sgc_publicacoes/anais01cv2_pt.pdf >. Acesso em 19 Mai 2019

PAGNANI, K.J.R, CASTRO, A.F.P. suínos em granjas dos Estados de São Paulo, Minas Gerais e Paraná. Pesquisa Veterinária Brasileira, v.22, n.1, p.12, 2002. Disponível em: $<$ http://www.scielo.br/scielo.php?script=sci_arttext\&pid=S0100736X2002000100002\&lang=pt>. Acesso em 19 Mai 2019.

SANTOS, F.M. et al. Ocorrência e fatores de risco da infecção. Pesq. Vet. Bras., v.37, n.6, 2017, p. 570-576. Disponível em:

<http://www.scielo.br/scielo.php?script=sci_arttext\&pid=S0100-

736X2017000600570\&lang=pt>. Acesso em 27 Jun 2019.

Interface Tecnológica - v. 16 n. 2 (2019) 
Saúde Animal. Verme suíno pode causar doença grave em humanos. Portal Suíno e Aves, 2012. Disponível em: <https://www.portalsuinoseaves.com.br/verme-suino-pode-causar-doencagrave-em-humanos/> Acesso 23 Ago 2019.

VANNUCCI, F.A, Identification and complete genome of Seneca Valley virus in vesicular fluid and sera of pigs affected with idiopathic vesicular disease, Brazil. Transboundary and Emerging Diseases, v.62, p.589-593, 2015. Disponível em:

<https://onlinelibrary.wiley.com/doi/full/10.1111/tbed.12410>. Acesso em: 27 Fev 2019.

ZANELLA, A.R.C, MORÉS, N. BARCELLOS, D.E.S.N. Principais ameaças sanitárias endêmicas da cadeia produtiva de suínos no Brasil. Pesquisa agropecuária Brasileira, v.51, n.5, p. 31-32, 2016. Disponível em:

$<$ http://www.scielo.br/scielo.php?script=sci_arttext\&pid=S0100-

204X2016000500443\&lang=pt>. Acesso em 27 Fev 2019. 